\title{
Concerted Catalysis by Nanocellulose and Proline in Organocatalytic Michael Additions
}

\author{
Naliharifetra Jessica Ranaivoarimanana $₫$, Kyohei Kanomata $₫$ and Takuya Kitaoka * \\ Department of Agro-Environmental Sciences, Graduate School of Bioresource and Bioenvironmental Sciences, \\ Kyushu University, 744 Motooka, Nishi-ku, Fukuoka 819-0395, Japan; jessi@agr.kyushu-u.ac.jp (N.J.R.); \\ kanomata@agr.kyushu-u.ac.jp (K.K.) \\ * Correspondence: tkitaoka@agr.kyushu-u.ac.jp; Tel.: +81-92-802-4665
}

Academic Editors: Theo Van de Ven and Amir Sheikhi

Received: 12 March 2019; Accepted: 27 March 2019; Published: 29 March 2019

\begin{abstract}
Cellulose nanofibers (CNFs) have recently attracted much attention as catalysts in various reactions. Organocatalysts have emerged as sustainable alternatives to metal-based catalysts in green organic synthesis, with concerted systems containing CNFs that are expected to provide next-generation catalysis. Herein, for the first time, we report that a representative organocatalyst comprising an unexpected combination of 2,2,6,6-tetramethylpiperidine 1-oxyl (TEMPO)-oxidized $\mathrm{CNFs}$ and proline shows significantly enhanced catalytic activity in an asymmetric Michael addition.
\end{abstract}

Keywords: nanocellulose; TEMPO-oxidized cellulose nanofiber; Michael addition; nitroalkene; organocatalysis; proline

\section{Introduction}

In the last two decades, cellulose nanofibers (CNFs) have emerged as a promising state-of-the-art nanomaterial with a wide range of applications [1]. Cellulose, which is a homopolymer of D-glucose that is connected by a $\beta-1,4$ linkage, is the most abundant, carbon-neutral, and renewable natural biomass on Earth. The regular assembly of dozens of molecular cellulose chains in one direction forms highly crystalline CNFs. CNFs are mainly derived from woody secondary cell walls and they possess an uncommon combination of features, such as high strength, high transparency, a large specific surface area, a well-defined nanoarchitecture, and a highly functionalized and chemically modifiable crystalline surface [2,3]. Taking advantage of these physicochemical properties, CNFs have been widely explored in polymer nanocomposite reinforcement [4] as high performance gas-separation films and purification membranes $[5,6]$ and in the confection of electroactive paper $[7,8]$.

Among the reported CNFs, 2,2,6,6-tetramethylpiperidine 1-oxyl (TEMPO)-oxidized cellulose nanofibers (TOCNs) are fascinating, owing to their simple and environmentally benign preparation method and unique nanoarchitecture [9]. In TOCNs, carboxylates are introduced onto native cellulose crystals at regular intervals and with high density, resulting in a core-shell structure, in which a glucose/glucuronic acid alternating copolymer covers native crystalline cellulose bundles. Furthermore, TEMPO oxidation of wood pulp affords completely individualized cellulose microfibrils, whose widths are the narrowest within the reported CNFs $(3-4 \mathrm{~nm})$. Therefore, the TOCN-derived materials have superior physical properties in gas-barrier films [10], free-standing aerogels [11], and nanocomposites [12].

While the material-oriented applications of CNFs have been extensively studied, another promising application of this new nanomaterial in catalytic molecular transformations has emerged [13-15]. The readily functionalizable nature of cellulose makes CNFs, especially TOCNs, a matrix of choice in the immobilization of metal nanoparticles and cations as catalysts [16]. We have recently reported the novel ability of TOCNs to accelerate catalytic reactions, in which TOCNs in 
protonated form (TOCN-H) act as a promising solid acid catalyst for the hydrolysis of acetals in their protonated form [17]. The surface carboxylic acids on TOCN-H behave as heterogeneous acid catalysts with activity that outperforms the corresponding homogeneous catalysts, such as acetic acid. Furthermore, we reported the ability of TOCNs, in their sodium form (TOCN-Na), to improve the efficiency of proline-catalyzed aldol reactions [18]. This finding provided a new method for enhancing less-efficient proline, which is a representative organocatalyst that has attracted considerable attention, owing to its environmentally benign nature, low cost, and wide availability [19]. Adding an external catalyst to TOCNs is an attractive method, owing to its potential applicability to a wide range of catalytic reactions. However, the scope of this methodology has yet to be explored.

The Michael reaction is an important carbon-carbon/heteroatom bond forming reaction in organic synthesis [20-25]. The Michael addition of ketones to nitroalkenes affords $\gamma$-nitroketones, which are essential building blocks in the preparation of various physiologically active compounds and pharmaceuticals [24,26,27]. Although proline is a promising catalyst in terms of its cost and availability for the synthesis of such compounds, high catalyst loading is required and the enantioselectivity is poor [28,29]. Much effort has been concentrated on remedying these issues by designing more efficient catalysts that are derived from the proline structure $[21,30,31]$, or by pairing proline with small organic molecules to form significantly more active complexes [32,33]. Methods using ionic liquids as solvents [34,35] and covalent anchoring to polymers, such as polyethylene glycol or polystyrene, to allow catalyst recovery, have also been investigated [36,37]. However, these strategies require additional catalyst preparation steps, resulting in additional costs that hamper their industrial application.

Herein, we report a new approach to enhancing the proline-catalyzed Michael reaction that takes advantage of CNFs. Adding TOCN-Na to the reaction medium greatly reduced the required proline catalyst loading and markedly enhanced the catalytic performance, rendering the process more economical, practical, and sustainable.

\section{Results and Discussion}

\subsection{Effects of Cellulose Nanofibers on Proline-Catalyzed Michael Additions}

The investigation into TOCN/proline-concerted catalysis of the Michael addition started with the reaction of cyclohexanone (1a) with trans- $\beta$-nitrostyrene (2a), which has been widely employed as a benchmark reaction to assess the related catalytic systems [38,39] (Table 1). The reaction with proline alone resulted in a low yield and poor enantioselectivity (entry 1). In contrast, adding the TOCN sodium salt (TOCN-Na) to the reaction medium significantly enhanced the yield under the same reaction conditions (entry 2). Notably, the diastereoselectivity and the enantioselectivity were somewhat improved in the presence of TOCNs, which is in contrast to our previous TOCN-assisted aldol reaction, resulting in poor stereoselectivity [18]. In this TOCN/proline-concerted system, an aqueous TOCN suspension was employed, replacing the water with $\mathrm{MeOH}$ by repetitive centrifugation before use. $\mathrm{MeOH}$ is known to improve the enantioselectivity of the proline-catalyzed Michael additions, although these reactions require several days to reach completion [29] (Table S1). Previous theoretical studies have shown that the explicit participation of $\mathrm{MeOH}$ molecules in the transition state influences the preferred approach between the enamine, which formed from proline and cyclohexanone, and nitrostyrene as the electrophile, leading to higher enantioselectivity in the formation of 3aa [40]. Accordingly, dissolving the proline in a small portion of $\mathrm{MeOH}$ prior to its addition to $\mathrm{N}, \mathrm{N}$-dimethylformamide (DMF) further increased both the yield and enantioselectivity (entry 3). No additional effects were recorded while using the same amount of $\mathrm{MeOH}$ in the reaction without TOCNs (56\% yield, syn:anti $=96: 4,34 \%$ ee for syn in $24 \mathrm{~h}$ ). Using TOCNs alone without proline did not promote the reaction, clearly suggesting that the cooperation of catalytically inactive TOCNs and low-activity proline was critical in enhancing the reaction efficiency of this Michael addition (entry 4). Interestingly, freeze-dried TOCNs, which were poorly dispersed in the solvent, owing to 
severe aggregation [11], also achieved a high yield, but the enantioselectivity remained low (entry 5). The intrinsic chirality of TOCNs might not be involved in imparting enantioselectivity, because using $(R)$-proline provided the same type of enhancement (entry 6). A plausible factor was the numerous carboxylate groups that are present on the TOCN surface, as confirmed by using homogeneously dispersed sodium acetate with an equivalent carboxy group content to the TOCNs used, which also slightly augmented the reaction yield (entry 7). However, this was not a dominant factor. The influence of functional groups was also investigated while using freshly prepared TOCNs with low carboxy contents (entry 9), which resulted in lower yields, but similar improvements in enantioselectivity. Furthermore, the crystalline nature of TOCN would be essential in the present catalytic system, with amorphous carboxymethylcellulose failing to promote the reaction at all (entry 8), despite both of the cellulose derivatives containing plentiful carboxy groups in their structures. Consequently, TOCN-Na containing $1.61 \mathrm{mmol} / \mathrm{g}$ of -COONa groups (entry 3) gave the best compromise in the yield/enantioselectivity enhancements, and it was used in subsequent experiments.

Table 1. Catalytic behavior of proline combined with cellulose nanofibers and additives in the Michael addition $^{\text {a }}$.

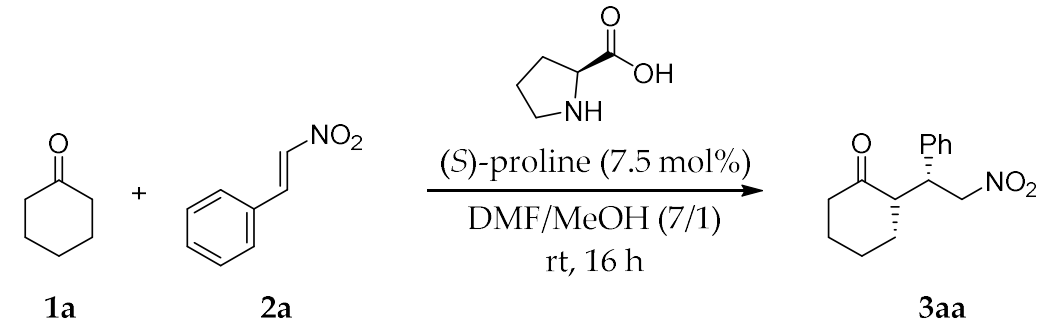

\begin{tabular}{ccccc}
\hline Entry & Additive & Yield (\%) $^{\mathbf{b}}$ & syn: $\boldsymbol{a n t i}^{\mathbf{c}}$ & $\boldsymbol{e e}$ for $\boldsymbol{s y n}(\mathbf{\%})^{\mathbf{c}}$ \\
\hline $1^{\mathrm{d}}$ & None & 35 & $89: 11$ & 32 \\
$3^{\mathrm{d}}$ & TOCN & 78 & $90: 10$ & 35 \\
$4^{\mathrm{e}}$ & TOCN & 88 & $90: 10$ & 43 \\
$5^{\mathrm{f}}$ & TOCN & Trace & - & - \\
$6^{\mathrm{g}}$ & TOCN & 81 & $95: 5$ & 33 \\
$7^{\mathrm{h}}$ & TOCN & 86 & $93: 7$ & -39 \\
$8^{\mathrm{h}}$ & Codium acetate & 41 & $89: 11$ & 6 \\
$9^{\mathrm{i}}$ & Carboxymethylcellulose & 34 & $90: 10$ & 27 \\
& TOCN/low & 42 & $82: 18$ & 42
\end{tabular}

a Unless otherwise noted, the reaction was performed using cyclohexanone (1a) (4 mL, excess), trans- $\beta$-nitrostyrene (2a) $(74.6 \mathrm{mg}, 0.50 \mathrm{mmol})$, (S)-proline $(7.5 \mathrm{~mol} \%)$, and 2,2,6,6-tetramethylpiperidine 1-oxyl (TEMPO)-oxidized cellulose nanofibers-Na (TOCN-Na) (100 mg dry weight) in a mixture of DMF (14 mL) and MeOH (2 mL). Aqueous medium of TOCN suspension was replaced with $\mathrm{MeOH}$ by repetitive centrifugation prior to reaction; ${ }^{\mathrm{b}}$ Isolated yield; ${ }^{\mathrm{c}}$ Determined by chiral stationary phase supercritical fluid chromatography (SFC) analysis; ${ }^{\mathrm{d}}$ Without $\mathrm{MeOH}$; ${ }^{\text {e }}$ Without (S)-proline; ${ }^{\mathrm{f}}$ Freeze-dried TOCN was added to the reaction; ${ }^{\mathrm{g}}(R)$-Proline was used instead of (S)-proline;

${ }^{\mathrm{h}}$ For entries 6 and 7 , additive amount adjusted to 1 eq. of $-\mathrm{COO}^{-}$groups contained in $100 \mathrm{mg}$ of TOCN (entry 3);

${ }^{\mathrm{i}} \mathrm{TOCN}$ with $-\mathrm{COO}^{-}$group content of $0.94 \mathrm{mmol} / \mathrm{g}$.

\subsection{Optimization of Reaction Conditions}

Different catalyst amounts and reaction temperatures were screened to identify the optimum conditions (Table 2). A lower amount of (S)-proline remained effective when combined with TOCNs (Table 2, entry 1), while higher catalyst loading led to a decrease in diastereoselectivity (entry 2). The optimum loading of $(S)$-proline was $7.5 \mathrm{~mol} \%$, relative to nitroalkene $\mathbf{2 a}$ (Table 1, entry 3 ). The yield and diastereoselectivity increased with an increasing temperature for reactions with and without TOCNs (Table 2, entries 3 and 4). The best result was obtained at $40{ }^{\circ} \mathrm{C}$ for $11 \mathrm{~h}$ in the presence of TOCNs (entry 4). With respect to green chemistry and sustainability, further reactions were conducted at room temperature, because the $(S)$-proline/TOCNs system efficiency at this temperature was close to that at $40{ }^{\circ} \mathrm{C}$. Testing different nitrostyrene/TOCNs ratios (entries 5-9) showed that the optimum weight 
ratio was 1:1.34 (entry 7). Indeed, increasing the TOCN quantity from $25 \mathrm{mg}$ to $100 \mathrm{mg}$ (entries 5-7) improved the catalytic efficiency from modest to high, while further increasing the amount of fibers gradually impeded the reaction. This might be attributed to reaction mixture thickening that causes crowding in the reaction medium (entries 8 and 9).

Table 2. Fine-tuning of catalyst amount, reaction temperature, and cellulose nanofiber quantity ${ }^{a}$.<smiles>O=C1CCCCC1</smiles>

$1 \mathbf{a}$

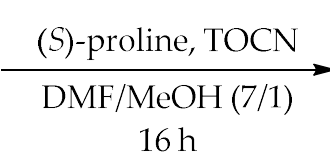

$16 \mathrm{~h}$<smiles>O=C1CCCCC1C[N+](=O)[O-]</smiles>

3aa

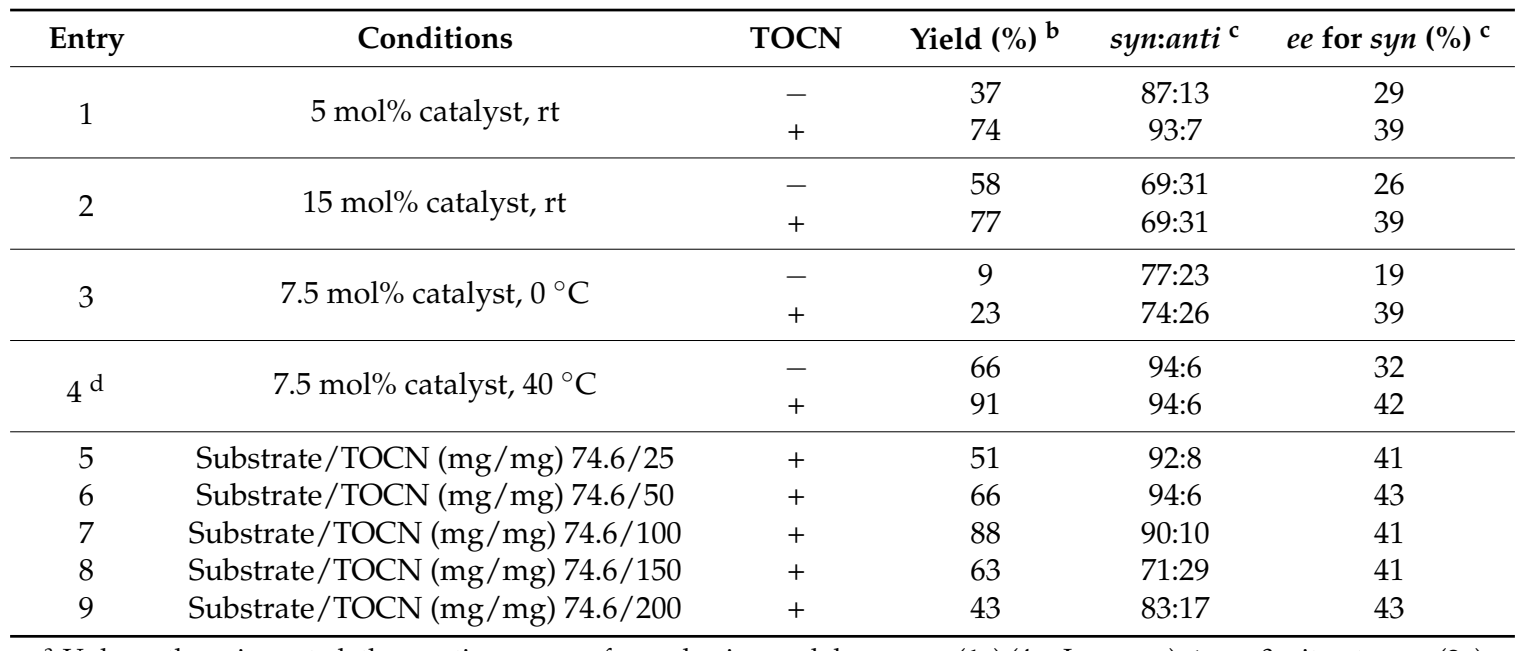

${ }^{a}$ Unless otherwise noted, the reaction was performed using cyclohexanone (1a) $(4 \mathrm{~mL}$, excess), trans- $\beta$-nitrostyrene (2a) (74.6 mg, $0.50 \mathrm{mmol}),(S)$-proline (7.5 mol\%), and TOCN-Na (100 mg dry weight) in a mixture of DMF (14 mL) and $\mathrm{MeOH}(2 \mathrm{~mL})$. Aqueous medium of TOCN suspension was replaced with $\mathrm{MeOH}$ by repetitive centrifugation prior to reaction; ${ }^{\mathrm{b}}$ Isolated yield; ${ }^{\mathrm{c}}$ Determined by chiral stationary phase SFC analysis; ${ }^{\mathrm{d}}$ Stirred for $11 \mathrm{~h}$.

\subsection{Substrate Scope}

With optimum conditions in hand, the substrate scope of the present catalyst system was investigated (Table 3). TOCNs clearly enhanced the reaction efficiency and the stereoselectivity of proline-catalyzed Michael additions of various substrates. Both electron-donating and electron-withdrawing groups on the nitrostyrene phenyl ring were compatible with the catalytic system, affording moderate to high yields and excellent diastereoselectivities in the presence of TOCNs (entries 1 and 2). In both cases the enantioselectivity was increased. Naphthyl-substituted nitroalkene, which has inherently high reactivity, as exemplified by a high yield without TOCNs, also benefited from the effect of TOCNs, which afforded increased enantioselectivity (entry 3). The generality of ketones, as the nucleophile activated by proline, was also studied in the reaction with trans- $\beta$-nitrostyrene. A significant increase in yield was observed for 4-oxothiane, which is a cyclic ketone bearing a heteroatom (entry 4). Unfortunately, the reaction yield with cyclopentanone was diminished in the presence of TOCNs, despite markedly increased enantioselectivity (entry 5). Acetone, the simplest ketone without a cyclic structure, was also applicable to the present catalytic system (entry 6). 
Table 3. Substrate scope ${ }^{\mathrm{a}}$.

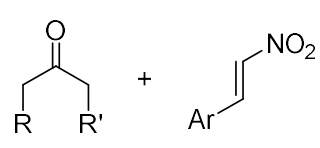

1

2

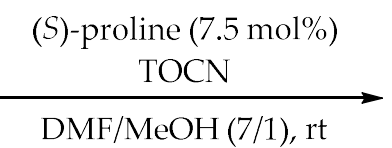<smiles>[R]CC(=O)C([R])C[N+](=O)[O-]</smiles>

3

\begin{tabular}{|c|c|c|c|c|c|c|c|}
\hline Entry & Substrates & Product & $\begin{array}{l}\text { Time } \\
\text { (h) }\end{array}$ & TOCN & Yield (\%) ${ }^{b}$ & syn:anti & $e e$ for syn $(\%)^{c}$ \\
\hline \multirow{2}{*}{1} & & & 48 & - & 26 & $90: 10^{d}$ & 31 \\
\hline & & & 48 & + & 68 & $93: 7^{d}$ & 35 \\
\hline \multirow{2}{*}{2} & & & 24 & - & 59 & $96: 4^{\mathrm{c}}$ & 28 \\
\hline & & & 24 & + & 83 & $95: 5^{c}$ & 50 \\
\hline \multirow{2}{*}{3} & & & 48 & - & 75 & $87: 13^{d}$ & 10 \\
\hline & & & 48 & + & 71 & $87: 13^{d}$ & 21 \\
\hline \multirow{2}{*}{4} & & & 24 & - & 18 & $94: 6^{d}$ & 24 \\
\hline & & & 24 & + & 76 & $97: 3^{d}$ & 38 \\
\hline \multirow{2}{*}{5} & & & 24 & - & 43 & $61: 39^{c}$ & 29 \\
\hline & $1 \mathrm{c}$ & & 24 & + & 12 & $72: 28^{c}$ & 59 \\
\hline & & & 24 & - & 32 & - & 10 \\
\hline & $1 \mathrm{~d}$ & & 24 & + & 70 & - & 23 \\
\hline
\end{tabular}

${ }^{a}$ Unless otherwise noted, the reactions were performed using an excess of ketone $\mathbf{1}$ ( $4 \mathrm{~mL}$ for all entries, except 10 eq. of $\mathbf{1 b}$ in entry 4$)$ and nitrostyrene (2) $(0.50 \mathrm{mmol}) ;{ }^{b}$ Isolated yield; ${ }^{\mathrm{c}}$ Determined by chiral stationary phase SFC analysis;

${ }^{\mathrm{d}}$ Determined by ${ }^{1} \mathrm{H}-\mathrm{NMR}$.

\section{Materials and Methods}

\subsection{General}

Nippon Paper Industries Co., Ltd. (Tokyo, Japan) kindly supplied TEMPO-oxidized cellulose nanofibers (TOCNs, carboxylate content: $1.61 \mathrm{mmol} / \mathrm{g}$ ), and they were used in reactions, except for Table 1, entry 9. TOCNs with a low carboxylate content used in Table 1, entry 8, were prepared from cellulose nanofibers purchased from Sugino Machine Limited (BiNFi-s AFo-10002, Uozu, Japan) according to a literature method $[17,41]$. Transmission electronic microscopy (TEM) with a JEM-2100HCKM microscope (JEOL, Tokyo, Japan) at the Ultramicroscopy Research Center, Kyushu University and powder X-ray diffraction (XRD) using a Rigaku MultiFlex diffractometer (Rigaku Corporation., Tokyo, Japan) at the Center of Advanced Instrumental Analysis, Kyushu University (see Figures S1 and S2, respectively, in Supplementary Materials) characterized the TOCN samples. The substrates $\mathbf{2 c}$ and $\mathbf{2 d}$ were synthesized according to a previously-reported method (detailed in the Supplementary Materials) [42]. Other reagents were purchased from Sigma-Aldrich Co. LLC. (Tokyo, Japan), FUJIFILM Wako Pure Chemical Industries, Ltd. (Osaka, Japan), and Tokyo Chemical Industry Co., Ltd. (Tokyo, Japan), and they were used without further purification. Thin-layer chromatography (TLC) analysis was performed on glass-backed plates precoated with silica gel (silica gel 60 GF254, $0.25 \mathrm{~mm}$ Merck, Tokyo, Japan). Column chromatography was performed while using an automated flash chromatography system (Smart Flash EPCLC-AI-580S, Yamazen, Osaka, Japan). The ${ }^{1} \mathrm{H}-$ and ${ }^{13} \mathrm{C}$-NMR spectra were recorded on a JNM-ECZ400 spectrometer (JEOL, Tokyo, Japan) at the Center 
of Advanced Instrumental Analysis, Kyushu University. Chemical shifts in the ${ }^{1} \mathrm{H}-\mathrm{NMR}$ spectra are reported in parts per million relative to the peak of tetramethylsilane (TMS, $\delta 0.00 \mathrm{ppm}$ ), used as an internal standard. The ${ }^{1} \mathrm{H}-\mathrm{NMR}$ data are reported, as follows: chemical shift, multiplicity ( $\mathrm{s}=$ singlet, $\mathrm{d}=$ doublet, $\mathrm{t}=$ triplet, $\mathrm{q}=$ quartet, $\mathrm{m}=$ multiplet $)$, coupling constants $(\mathrm{Hz})$, and integration. ${ }^{13} \mathrm{C}-\mathrm{NMR}$ spectra were recorded with complete proton decoupling, and chemical shifts are reported in parts per million relative to the solvent resonance $\left(\mathrm{CDCl}_{3}, \delta 77.0 \mathrm{ppm}\right)$, used as an internal standard.

\subsection{Preparation of TOCNs with Low Carboxylate Content}

Wet-state cellulose nanofibers ( $3.0 \mathrm{~g}$ dry weight of cellulose) were suspended in deionized water $(300 \mathrm{~mL})$ containing TEMPO $(48 \mathrm{mg})$ and $\mathrm{NaBr}(300 \mathrm{mg})$. TEMPO-mediated oxidation was started by adding sodium hypochlorite $(2.0 \mathrm{mmol} / \mathrm{g}$ of cellulose) to the suspension. The mixture was stirred at room temperature for $30 \mathrm{~min}$, while the suspension was maintained at $\mathrm{pH} 10$ while using a $\mathrm{pH}$ titrator (GT-200 Automatic Titrator, Mitsubishi Chemical Analytech, Yamato, Japan) that was loaded with $\mathrm{NaOH}(0.5 \mathrm{M})$. The oxidation was quenched with ethanol $(10 \mathrm{~mL})$ and the suspension was washed thoroughly with deionized water by successive centrifugation at $22,540 \times g$ for $10 \mathrm{~min}$ (TOMMY Suprema 21 High-Speed Refrigerated Centrifuge, TOMMY Seiko, Tokyo, Japan). Nanofibrillation was conducted by aqueous counter collision with a high-pressure water jet system at $245 \mathrm{MPa}$ (0.1-mm diameter dual-nozzle chamber; Star Burst Labo, Sugino Machine Limited, Uozu, Japan) [43]. The obtained mixture was then centrifuged to separate the cellulose nanofiber as supernatant $(0.6 \mathrm{wt} \%)$ from the unfibrillized fibers $(10 \mathrm{~min}, 22,540 \times \mathrm{g})$. Electrical conductivity titration confirmed the carboxylate content of the TOCNs [41].

\subsection{Water Removal Process from Nanocellulose Samples}

Each nanocellulose was subjected to solvent exchange to remove water prior to use, because water inhibited the reaction, except for that in entry 4 in Table 1, which was then freeze-dried. To obtain freeze-dried samples, TOCN water suspension $(10 \mathrm{~mL}, 1.04 \mathrm{wt} \%)$ was mixed with tertiary butanol (30 mL), frozen in liquid nitrogen, and dried under vacuum (Scanvac CoolSafe LaboGene, Sakuma Seisakusho, Co. Ltd., Tokyo, Japan). Washing the TOCN water suspension (10 mL, $1.04 \mathrm{wt} \%)$ with $\mathrm{MeOH}(30 \mathrm{~mL})$ by centrifugation $(9200 \times g, 5 \mathrm{~min})$ five times was undertaken to perform the solvent exchange process.

3.4. Representative Procedure for the Proline-Catalyzed Michael Addition of Cyclohexanone to trans- $\beta$-Nitrostyrene in the Presence of TOCNs

Cyclohexanone (1a) $(4.0 \mathrm{~mL}$, excess) and trans- $\beta$-nitrostyrene (2a) $(74.6 \mathrm{mg}, 0.50 \mathrm{mmol})$ were added to the reaction medium, followed by a solution of (S)-proline ( $4.4 \mathrm{mg}, 7.5 \mathrm{~mol} \%$ with respect to $2 \mathrm{a})$ in $\mathrm{MeOH}(2.0 \mathrm{~mL})$. The resulting mixture was stirred at room temperature and TLC monitored progress. Upon completion, the reaction was quenched by adding aq. $\mathrm{NH}_{4} \mathrm{Cl}$, extracted with dichloromethane $(30 \mathrm{~mL} \times 3)$, and dried over $\mathrm{Na}_{2} \mathrm{SO}_{4}$. Purification of the concentrated organic layer by column chromatography (hexane and ethyl acetate as eluents) rendered product 3aa as a white solid (108.8 mg, $88 \%$ ). The enantiomeric and diastereomeric ratios of the reactions were measured by supercritical fluid chromatography (SFC) while using a chiral stationary phase (ACQUITY UPC2, Waters, Tokyo, Japan). The spectroscopic data of each product were in agreement with previously reported data [39,44].

Spectroscopic Data

(S)-2-((R)-2-Nitro-1-phenylethyl)cyclohexanone (3aa) [44]. White solid (108.8 mg, 88\%); ${ }^{1} \mathrm{H}-\mathrm{NMR}$ (400 MHz, $\mathrm{CDCl}_{3}$ ) syn-3aa: $\delta 7.34-7.28(\mathrm{~m}, 3 \mathrm{H}), 7.18-7.15(\mathrm{~m}, 2 \mathrm{H}), 4.94(\mathrm{dd}, J=12.4,4.4 \mathrm{~Hz}, 1 \mathrm{H}), 4.64$ $(\mathrm{dd}, J=12.4,10.0 \mathrm{~Hz}, 1 \mathrm{H}), 3.76(\mathrm{dd}, J=10.0,4.8 \mathrm{~Hz}, 1 \mathrm{H}), 2.73-2.66(\mathrm{~m}, 1 \mathrm{H}), 2.51-2.35(\mathrm{~m}, 2 \mathrm{H}), 2.12-2.04$ $(\mathrm{m}, 1 \mathrm{H}), 1.82-1.51(\mathrm{~m}, 4 \mathrm{H}), 1.29-1.19(\mathrm{~m}, 1 \mathrm{H})$; detectable peaks of anti-3aa: $\delta 4.89-4.81(\mathrm{~m}, 0.1 \mathrm{H})$, 4.04-3.99 (m, 0.05H), 2.76-2.75 (m, overlapped with syn-3aa, 0.04H), 2.30-2.24 (m, overlapped with syn-3aa, $0.02 \mathrm{H}), 1.92-1.84(\mathrm{~m}, 0.04 \mathrm{H}), 1.43-1.34(\mathrm{~m}, 0.05 \mathrm{H}) ;{ }^{13} \mathrm{C}-\mathrm{NMR}\left(100.5 \mathrm{MHz}, \mathrm{CDCl}_{3}\right)$ syn-3aa: 
$\delta 211.9,137.7,128.8,128.1,127.6,78.8,52.4,43.8,42.6,33.1,28.4,24.9$; detectable peaks of anti-3aa: $\delta 210.4,138.3,128.6,128.2,127.4,76.4,53.7,42.9,42.2,29.8,27.3$; SFC: Daicel Chiralpak IC-3 $(\lambda=210 \mathrm{~nm}$, $\mathrm{CO}_{2} / 2$-propanol, 93:7, $\left.1.0 \mathrm{~mL} / \mathrm{min}, 30^{\circ} \mathrm{C}\right), \mathrm{t}_{\mathrm{r}}($ major $)=3.56 \mathrm{~min}, \mathrm{t}_{\mathrm{r}}($ minor $)=4.70 \mathrm{~min}$.

(S)-2-((R)-1-(4-Methoxyphenyl)-2-nitroethyl)cyclohexanone (3ab) [44]. Yellow solid (94.6 mg, 68\%); ${ }^{1} \mathrm{H}-\mathrm{NMR}\left(400 \mathrm{MHz}, \mathrm{CDCl}_{3}\right)$ syn-3ab: $\delta 7.08(\mathrm{~d}, J=8.4 \mathrm{~Hz}, 2 \mathrm{H}), 6.85(\mathrm{~d}, J=8.8 \mathrm{~Hz}, 2 \mathrm{H}), 4.91(\mathrm{dd}$, $J=12.4,4.8 \mathrm{~Hz}, 1 \mathrm{H}), 4.58(\mathrm{dd}, J=12.4,10.0 \mathrm{~Hz}, 1 \mathrm{H}), 3.78(\mathrm{~s}, 3 \mathrm{H}), 3.74-3.68(\mathrm{~m}, 1 \mathrm{H}), 2.68-2.61(\mathrm{~m}, 1 \mathrm{H})$, 2.50-2.34 (m, 2H), 2.11-2.04 (m, 1H), 1.82-1.52 (m, 4H), 1.28-1.18 (m, 1H); detectable peaks of anti-3ab: 反 7.20-7.16 (m, 0.09H), 4.87-4.71 (m, 0.13H), 3.96-3.88 (m, 0.06H); ${ }^{13} \mathrm{C}-\mathrm{NMR}\left(100.5 \mathrm{MHz}, \mathrm{CDCl}_{3}\right)$ syn-3ab: $\delta$ 212.0, 158.8, 129.4, 129.0, 114.1, 79.0, 55.1, 52.5, 43.1, 42.6, 33.0, 28.4, 24.9; detectable peaks of anti-3ab: $\delta 210.6,158.7,129.3,113.9,76.9,53.7,42.4,42.2,30.0,27.2$; SFC: Daicel Chiralpak AD-3, $\left(\lambda=220 \mathrm{~nm}, \mathrm{CO}_{2} /\right.$ methanol, 95:5, $\left.1.0 \mathrm{~mL} / \mathrm{min}, 30^{\circ} \mathrm{C}\right), \mathrm{t}_{\mathrm{r}}($ minor $)=5.90 \mathrm{~min}, \mathrm{t}_{\mathrm{r}}($ major $)=8.61 \mathrm{~min}$.

(S)-2-((R)-1-(4-Bromophenyl)-2-nitroethyl)cyclohexanone (3ac) [44]. White solid (135.7 mg, 83\%); ${ }^{1} \mathrm{H}-\mathrm{NMR}$ $\left(400 \mathrm{MHz}, \mathrm{CDCl}_{3}\right)$ syn-3ac: $\delta 7.48-7.43(\mathrm{~m}, 2 \mathrm{H}), 7.20-7.04(\mathrm{~m}, 2 \mathrm{H}), 4.93(\mathrm{dd}, J=12.8,4.6 \mathrm{~Hz}, 1 \mathrm{H})$, $4.60(\mathrm{dd}, J=12.8,10.1 \mathrm{~Hz}, 1 \mathrm{H}), 3.75(\mathrm{td}, J=9.8,4.4 \mathrm{~Hz}, 1 \mathrm{H}), 2.68-2.62(\mathrm{~m}, 1 \mathrm{H}), 2.50-2.45(\mathrm{~m}, 1 \mathrm{H})$, 2.42-2.33 (m, 1H), 2.12-2.06 (m, 1H), 1.83-1.55 (m, 4H), $1.23(\mathrm{qd}, J=12.4,3.5 \mathrm{~Hz}, 1 \mathrm{H})$; detectable peaks of anti-3ac: $\delta 7.44-7.43(\mathrm{~m}, 0.26 \mathrm{H}), 7.16-7.14(\mathrm{~m}, 0.21 \mathrm{H}), 4.89-4.78(\mathrm{~m}, 0.21 \mathrm{H}), 3.94-3.89(\mathrm{~m}, 0.12 \mathrm{H})$, 2.75-2.70 (m, overlapped with syn-3ac, $0.11 \mathrm{H}), 1.94-1.87(\mathrm{~m}, 0.13 \mathrm{H}), 1.42-1.31(\mathrm{~m}, 0.11 \mathrm{H}) ;{ }^{13} \mathrm{C}-\mathrm{NMR}$ (100.5 MHz, CDCl ${ }_{3}$ ) syn-3ac: $\delta 211.4,136.8,131.9,129.8,121.5,78.4,52.1,43.3,42.6,33.0,28.3,24.9$; detectable peaks of anti-3ac: $\delta 210.2,137.3,131.7,130.1,76.4,53.4,42.2,30.0,27.2$; SFC: Daicel Chiralpak IC-3, $\left(\lambda=220 \mathrm{~nm}, \mathrm{CO}_{2} / 2\right.$-propanol, 95:5, $\left.1.0 \mathrm{~mL} / \mathrm{min}, 30^{\circ} \mathrm{C}\right), \mathrm{t}_{\mathrm{r}}$ (major $)=6.22 \mathrm{~min}, \mathrm{t}_{\mathrm{r}}$ (minor $)=9.62 \mathrm{~min}$.

(S)-2-((R)-1-Naphthyl-2-nitroethyl)cyclohexanone (3ad) [44]. Off-white solid (105.1 mg, 71\%); ${ }^{1} \mathrm{H}-\mathrm{NMR}$ $\left(400 \mathrm{MHz}, \mathrm{CDCl}_{3}\right)$ syn-3ad: $87.82-7.77(\mathrm{~m}, 3 \mathrm{H}), 7.67(\mathrm{~d}, J=26.5 \mathrm{~Hz}, 1 \mathrm{H}), 7.49-7.44(\mathrm{~m}, 2 \mathrm{H}), 7.30-7.25$ $(\mathrm{m}, 1 \mathrm{H}), 5.03(\mathrm{dd}, J=12.6,4.3 \mathrm{~Hz}, 1 \mathrm{H}), 4.72(\mathrm{dd}, J=12.8,10.1 \mathrm{~Hz}, 1 \mathrm{H}), 3.95(\mathrm{td}, J=10.1,4.1 \mathrm{~Hz}$, $1 \mathrm{H}), 2.76(\mathrm{td}, J=11.1,4.6 \mathrm{~Hz}, 1 \mathrm{H}), 2.49-2.32(\mathrm{~m}, 2 \mathrm{H}), 2.05-2.00(\mathrm{~m}, 1 \mathrm{H}), 1.71-1.49(\mathrm{~m}, 4 \mathrm{H}), 1.28-1.19$ $(\mathrm{m}, 1 \mathrm{H})$; detectable peaks of anti-3ad: $\delta 7.69(\mathrm{~s}, 0.12 \mathrm{H}), 7.39-7.36(\mathrm{~m}, 0.11 \mathrm{H}), 4.96-4.93(\mathrm{~m}, 0.13 \mathrm{H})$, $4.20-4.15(\mathrm{~m}, 0.08 \mathrm{H}), 2.24(\mathrm{~m}, 0.07 \mathrm{H}), 1.85-1.76(\mathrm{~m}, 0.08 \mathrm{H}), 1.42-1.29(\mathrm{~m}$, overlapped with syn-3ad, $0.04 \mathrm{H})$; ${ }^{13} \mathrm{C}-\mathrm{NMR}\left(100.5 \mathrm{MHz}, \mathrm{CDCl}_{3}\right.$ ) syn-3ad: $\delta 211.8,135.0,133.2,132.7,128.7,127.7,127.5,126.3$, 126.0, 125.1, 78.7, 52.3, 44.0, 42.6, 33.2, 28.4, 24.9; detectable peaks of anti-3ad: $\delta 210.4,135.8,133.1$, 132.5, 128.4, 127.5, 126.9, 126.4, 126.2, 126.0, 76.4, 53.7, 42.9, 42.2, 29.8, 27.2; SFC: Daicel Chiralpak OD-3, $\left(\lambda=210 \mathrm{~nm}, \mathrm{CO}_{2} / 2\right.$-propanol, 82:18, $\left.1.0 \mathrm{~mL} / \mathrm{min}, 30^{\circ} \mathrm{C}\right), \mathrm{t}_{\mathrm{r}}($ major $)=1.34 \mathrm{~min}, \mathrm{t}_{\mathrm{r}}$ (minor $)=1.73 \mathrm{~min}$.

(S)-3-((R)-2-Nitro-1-phenylethyl)tetrahydro-4H-thiopyran-4-one (3ba) [39]. White solid (100.8 mg, 76\%); ${ }^{1} \mathrm{H}-\mathrm{NMR}\left(400 \mathrm{MHz}, \mathrm{CDCl}_{3}\right)$ syn-3ba: $\delta 7.36-7.17(\mathrm{~m}, 5 \mathrm{H}), 4.73(\mathrm{dd}, J=12.8,4.6 \mathrm{~Hz}, 1 \mathrm{H}), 4.61(\mathrm{dd}$, $J=12.8,9.6 \mathrm{~Hz}, 1 \mathrm{H}), 3.96(\mathrm{td}, J=10.3,4.7 \mathrm{~Hz}, 1 \mathrm{H}), 3.06-2.93(\mathrm{~m}, 3 \mathrm{H}), 2.87-2.77(\mathrm{~m}, 2 \mathrm{H}), 2.62-2.41(\mathrm{~m}, 2 \mathrm{H})$; detectable peaks of anti-3ba: $\delta 4.90-4.81(\mathrm{~m}, 0.02 \mathrm{H}), 4.18-4.13(\mathrm{~m}, 0.03 \mathrm{H}), 2.94-2.92(\mathrm{~m}$, overlapped with syn-3ba, $0.06 \mathrm{H}) ;{ }^{13} \mathrm{C}-\mathrm{NMR}\left(100.5 \mathrm{MHz}, \mathrm{CDCl}_{3}\right)$ syn-3ba: $\delta 209.5,136.4,129.3,128.3,128.1,78.6$, 54.9, 44.5, 43.4, 35.1, 31.6; detectable peak of anti-3ba: $\delta 129.0$; SFC: Daicel Chiralpak IC-3, $(\lambda=210 \mathrm{~nm}$, $\mathrm{CO}_{2} /$ methanol, $\left.96: 4,1.0 \mathrm{~mL} / \mathrm{min}, 30^{\circ} \mathrm{C}\right), \mathrm{t}_{\mathrm{r}}($ major $)=2.41 \mathrm{~min}, \mathrm{t}_{\mathrm{r}}($ minor $)=2.75 \mathrm{~min}$.

(S)-2-((R)-2-Nitro-1-phenylethyl)cyclopentan-1-one (3ca) [44]. Off-white solid (13.7 mg, 12\%); ${ }^{1} \mathrm{H}-\mathrm{NMR}$ $\left(400 \mathrm{MHz}, \mathrm{CDCl}_{3}\right)$ syn-3ca: $\delta 7.32(\mathrm{~s}, 3 \mathrm{H}), 7.14(\mathrm{~s}, 2 \mathrm{H}), 5.32(\mathrm{dd}, J=12.8,5.5 \mathrm{~Hz}, 1 \mathrm{H}), 5.00(\mathrm{~d}, J=7.8 \mathrm{~Hz}$, $1 \mathrm{H}), 4.70(\mathrm{dd}, J=12.8,10.1 \mathrm{~Hz}, 1 \mathrm{H}), 3.82(\mathrm{dd}, J=11.9,7.8 \mathrm{~Hz}, 1 \mathrm{H}), 3.71-3.65(\mathrm{~m}, 1 \mathrm{H}), 2.36(\mathrm{~d}, J=43.9 \mathrm{~Hz}$, $1 \mathrm{H}), 2.12(\mathrm{~d}, J=41.6 \mathrm{~Hz}, 1 \mathrm{H}), 1.89(\mathrm{~d}, J=49.4 \mathrm{~Hz}, 1 \mathrm{H}), 1.70(\mathrm{~d}, J=34.8 \mathrm{~Hz}, 1 \mathrm{H}), 1.47(\mathrm{~d}, J=41.6 \mathrm{~Hz}$, $1 \mathrm{H})$; detectable peaks of anti-3ca: $\delta 7.42-7.41(\mathrm{~m}, 0.12 \mathrm{H}), 7.13-7.05(\mathrm{~m}, 0.18 \mathrm{H}), 3.83(\mathrm{td}, J=7.8,4.1 \mathrm{~Hz}$, $0.34 \mathrm{H}), 2.29-2.25(\mathrm{~m}$, overlapped with syn-3ca, $0.16 \mathrm{H}), 1.41-1.20(\mathrm{~m}, 0.17 \mathrm{H}) ;{ }^{13} \mathrm{C}-\mathrm{NMR}(100.1 \mathrm{MHz}$, $\mathrm{CDCl}_{3}$ ) syn-3ca: $\delta 218.5,137.7,128.9,128.4,127.9,78.2,50.4,44.1,38.6,28.3,20.0$; detectable peaks of anti-3ca: $\delta$ 219.1, 137.3, 128.9 (overlapped with syn-3ca), 77.1, 51.4, 44.0, 39.2, 27.0, 20.5; SFC: Daicel Chiralpak IA-3, $\left(\lambda=210 \mathrm{~nm}, \mathrm{CO}_{2} / 2\right.$-propanol, $\left.95: 5,1.0 \mathrm{~mL} / \mathrm{min}, 30^{\circ} \mathrm{C}\right), \mathrm{t}_{\mathrm{r}}($ minor $)=1.70 \mathrm{~min}, \mathrm{t}_{\mathrm{r}}($ major $)$ $=2.56 \mathrm{~min}$. 
(R)-5-Nitro-4-phenylpentan-2-one (3da) [39]. White solid (72.3 mg, 70\%); ${ }^{1} \mathrm{H}-\mathrm{NMR}\left(400 \mathrm{MHz}, \mathrm{CDCl}_{3}\right)$ : $\delta 7.33-7.19(\mathrm{~m}, 5 \mathrm{H}), 4.62(\mathrm{ddd}, J=40.0,12.3,7.5 \mathrm{~Hz}, 2 \mathrm{H}), 4.03-3.95(\mathrm{~m}, 1 \mathrm{H}), 2.89(\mathrm{~d}, J=7.3 \mathrm{~Hz}, 2 \mathrm{H})$, 2.09 (s, 3H); ${ }^{13} \mathrm{C}-\mathrm{NMR}\left(100.5 \mathrm{MHz}, \mathrm{CDCl}_{3}\right): \delta 205.4,138.8,128.9,127.7,127.3,79.3,46.0,38.9,30.2$; SFC: Daicel Chiralpak IC-3, $\left(\lambda=210 \mathrm{~nm}, \mathrm{CO}_{2} / 2\right.$-propanol, 93:7, $\left.1.0 \mathrm{~mL} / \mathrm{min}, 30^{\circ} \mathrm{C}\right), \mathrm{t}_{\mathrm{r}}($ major $)=3.05 \mathrm{~min}$, $\mathrm{t}_{\mathrm{r}}($ minor $)=3.50 \mathrm{~min}$.

\section{Conclusions}

We have developed a novel method that substantially enhanced the proline-catalyzed Michael additions of ketones to nitroalkenes through the simple incorporation of nanocellulose, TOCNs, in the reaction medium at room temperature. We assumed that crystalline TOCNs with densely packed surface carboxylate groups played a significant role in increasing the catalytic activity, because TOCNs with low carboxylate content only gave a small yield enhancement. In addition, molecular carboxylates that originated from sodium acetate gave a modestly improved yield, while the amorphous carboxylated cellulose derivative was not effective. Furthermore, the efficiency of the catalytic system was directly related to the amount of nanocellulose used. The method was successfully applied to different ketones and nitroalkene substrates. Concerted catalysis using nanocelluloses and organocatalysts provides new research avenues for both emerging applications of nanocellulose and green sustainable chemistry.

Supplementary Materials: The supplementary materials are available online.

Author Contributions: N.J.R. conducted all experiments and analysis. N.J.R. and K.K. wrote the manuscript. T.K. conceived the present idea, and K.K. and T.K. designed the research. All authors reviewed and approved the manuscript.

Funding: This research was supported by Advanced Low Carbon Technology Research and Development Program from Japan Science and Technology Agency (T.K.), by Research Scholarships from the Ministry of Education, Culture, Sports, Science and Technology, Japan (N.J.R.), and by Research Fellowships for Young Scientists from Japan Society for the Promotion of Science (K.K.).

Acknowledgments: The authors thank Nippon Paper Industries Co. Ltd. for kindly supplying TEMPO-oxidized cellulose nanofibers.

Conflicts of Interest: The authors declare no conflicts of interest. The funding sources had no role in the design of the study; in the collection, analyses, or interpretation of data; in the writing of the manuscript; or in the decision to publish the results.

\section{References}

1. Tayeb, A.H.; Amini, E.; Ghasemi, S.; Tajvidi, M. Cellulose nanomaterials-binding properties and applications: A review. Molecules 2018, 23, 2684. [CrossRef] [PubMed]

2. Habibi, Y.; Lucia, L.A.; Rojas, O.J. Cellulose nanocrystals: Chemistry, self-assembly, and applications. Chem. Rev. 2010, 110, 3479-3500. [CrossRef] [PubMed]

3. Habibi, Y. Key advances in the chemical modification of nanocelluloses. Chem. Soc. Rev. 2014, 43, 1519-1542. [CrossRef] [PubMed]

4. Wei, H.; Rodriguez, K.; Renneckar, S.; Vikesland, P.J. Environmental science and engineering applications of nanocellulose-based nanocomposites. Environ. Sci. Nano 2014, 1, 302-316. [CrossRef]

5. Fukuzumi, H.; Fujisawa, S.; Saito, T.; Isogai, A. Selective Permeation of Hydrogen Gas Using Cellulose Nanofibril Film. Biomacromolecules 2013, 14, 1705-1709. [CrossRef]

6. Ma, H.; Burger, C.; Hsiao, B.S.; Chu, B. Ultrafine Polysaccharide Nanofibrous Membranes for Water Purification. Biomacromolecules 2011, 12, 970-976. [CrossRef] [PubMed]

7. Nyström, G.; Mihranyan, A.; Razaq, A.; Lindström, T.; Nyholm, L.; Strømme, M. A nanocellulose polypyrrole composite based on microfibrillated cellulose from wood. J. Phys. Chem. B 2010, 114, 4178-4182. [CrossRef] [PubMed]

8. Koga, H.; Nogi, M.; Komoda, N.; Nge, T.T.; Sugahara, T.; Suganuma, K. Uniformly connected conductive networks on cellulose nanofiber paper for transparent paper electronics. NPG Asia Mater. 2014, 6, e93. [CrossRef] 
9. Isogai, A.; Saito, T.; Fukuzumi, H. TEMPO-oxidized cellulose nanofibers. Nanoscale 2011, 3, 71-85. [CrossRef]

10. Fukuzumi, H.; Saito, T.; Iwata, T.; Kumamoto, Y.; Isogai, A. Transparent and High Gas Barrier Films of Cellulose Nanofibers Prepared by TEMPO-Mediated Oxidation. Biomacromolecules 2009, 10, 162-165. [CrossRef]

11. Nemoto, J.; Saito, T.; Isogai, A. Simple Freeze-Drying Procedure for Producing Nanocellulose Aerogel-Containing, High-Performance Air Filters. ACS Appl. Mater. Interfaces 2015, 7, 19809-19815. [CrossRef] [PubMed]

12. Hamou, K.B.; Kaddami, H.; Dufresne, A.; Boufi, S.; Magnin, A.; Erchiqui, F. Impact of TEMPO-oxidization strength on the properties of cellulose nanofibril reinforced polyvinyl acetate nanocomposites. Carbohydr. Polym. 2018, 181, 1061-1070. [CrossRef] [PubMed]

13. Serizawa, T.; Sawada, T.; Wada, M. Chirality-specific hydrolysis of amino acid substrates by cellulose nanofibers. Chem. Commun. 2013, 49, 8827-8829. [CrossRef]

14. Koga, H.; Namba, N.; Takahashi, T.; Nogi, M.; Nishina, Y. Renewable Wood Pulp Paper Reactor with Hierarchical Micro/Nanopores for Continuous-Flow Nanocatalysis. ChemSusChem 2017, 10, 2560-2565. [CrossRef]

15. Kaushik, M.; Basu, K.; Benoit, C.; Cirtiu, C.M.; Vali, H.; Moores, A. Cellulose nanocrystals as chiral inducers: Enantioselective catalysis and transmission electron microscopy 3D characterization. J. Am. Chem. Soc. 2015, 137, 6124-6127. [CrossRef]

16. Kaushik, M.; Moores, A. Review: Nanocelluloses as versatile supports for metal nanoparticles and their applications in catalysis. Green Chem. 2016, 18, 622-637. [CrossRef]

17. Tamura, Y.; Kanomata, K.; Kitaoka, T. Interfacial Hydrolysis of Acetals on Protonated TEMPO-oxidized Cellulose Nanofibers. Sci. Rep. 2018, 8, 5021. [CrossRef] [PubMed]

18. Kanomata, K.; Tatebayashi, N.; Habaki, X.; Kitaoka, T. Cooperative catalysis of cellulose nanofiber and organocatalyst in direct aldol reactions. Sci. Rep. 2018, 8, 4098. [CrossRef] [PubMed]

19. List, B. Proline-catalyzed asymmetric reactions. Tetrahedron 2002, 58, 5573-5590. [CrossRef]

20. Berner, O.M.; Tedeschi, L.; Enders, D. Asymmetric Michael additions to nitroalkenes. Eur. J. Org. Chem. 2002, 2002, 1877-1894. [CrossRef]

21. Mase, N.; Watanabe, K.; Yoda, H.; Takabe, K.; Tanaka, F.; Barbas, C.F. Organocatalytic Direct Michael Reaction of Ketones and Aldehydes with $\beta$-Nitrostyrene in Brine. J. Am. Chem. Soc. 2006, 128, 4966-4967. [CrossRef]

22. Nising, C.F.; Bräse, S. Recent developments in the field of oxa-michael reactions. Chem. Soc. Rev. 2012, 41, 988-999. [CrossRef]

23. Enders, D.; Wang, C.; Liebich, J.X. Organocatalytic asymmetric aza-Michael additions. Chem. Eur. J. 2009, 15, 11058-11076. [CrossRef]

24. Alonso, D.A.; Baeza, A.; Chinchilla, R.; Gómez, C.; Guillena, G.; Pastor, I.M.; Ramón, D.J. Recent advances in asymmetric organocatalyzed conjugate additions to nitroalkenes. Molecules 2017, 22, 895. [CrossRef]

25. Zhang, Y.; Wang, W. Recent advances in organocatalytic asymmetric Michael reactions. Catal. Sci. Technol. 2012, 2, 42-53. [CrossRef]

26. Hayashi, Y.; Ogasawara, S. Time Economical Total Synthesis of (-)-Oseltamivir. Org. Lett. 2016, 18, 3426-3429. [CrossRef] [PubMed]

27. Sukhorukov, A.Y.; Sukhanova, A.A.; Zlotin, S.G. Stereoselective reactions of nitro compounds in the synthesis of natural compound analogs and active pharmaceutical ingredients. Tetrahedron 2016, 72, 6191-6281. [CrossRef]

28. List, B.; Pojarliev, P.; Martin, H.J. Efficient Proline-Catalyzed Michael Additions of Unmodified Ketones to Nitro Olefins. Org. Lett. 2001, 3, 2423-2425. [CrossRef]

29. Enders, D.; Seki, A. Proline-Catalyzed Enantioselective Michael Additions of Ketones to Nitrostyrene. Synlett 2002, 2002, 0026-0028. [CrossRef]

30. Chen, H.; Wang, Y.; Wei, S.; Sun, J. 1-Proline derived triamine as a highly stereoselective organocatalyst for asymmetric Michael addition of cyclohexanone to nitroolefins. Tetrahedron Asymmetry 2007, 18, 1308-1312. [CrossRef]

31. Cobb, A.J.A.; Longbottom, D.A.; Shaw, D.M.; Ley, S.V. 5-Pyrrolidin-2-yltetrazole as an asymmetric organocatalyst for the addition of ketones to nitro-olefins. Chem. Commun. 2004, 1808-1809. [CrossRef] [PubMed] 
32. Mandal, T.; Zhao, C.G. Modularly designed organocatalytic assemblies for direct nitro-Michael addition reactions. Angew. Chem. Int. Ed. 2008, 47, 7714-7717. [CrossRef] [PubMed]

33. Wang, W.H.; Abe, T.; Wang, X.B.; Kodama, K.; Hirose, T.; Zhang, G.Y. Self-assembled proline-amino thioureas as efficient organocatalysts for the asymmetric Michael addition of aldehydes to nitroolefins. Tetrahedron Asymmetry 2010, 21, 2925-2933. [CrossRef]

34. Porcar, R.; Burguete, M.I.; Lozano, P.; Garcia-Verdugo, E.; Luis, S.V. Supramolecular Interactions Based on Ionic Liquids for Tuning of the Catalytic Efficiency of (L)-Proline. ACS Sustain. Chem. Eng. 2016, 4, 6062-6071. [CrossRef]

35. Kotrusz, P.; Toma, S.; Schmalz, H.-G.; Adler, A. Michael Additions of Aldehydes and Ketones to $\beta$-Nitrostyrenes in an Ionic Liquid. Eur. J. Org. Chem. 2004, 2004, 1577-1583. [CrossRef]

36. Benaglia, M.; Cinquinia, M.; Cozzi, F.; Puglisi, A.; Celentano, G. Poly(ethylene-glycol)-supported proline: A recyclable aminocatalyst for the enantioselective synthesis of $\gamma$-nitroketones by conjugate addition. J. Mol. Catal. A Chem. 2003, 204-205, 157-163. [CrossRef]

37. Alza, E.; Cambeiro, X.C.; Jimenez, C.; Pericàs, M.A. Highly enantioselective Michael additions in water catalyzed by a PS-supported pyrrolidine. Org. Lett. 2007, 9, 3717-3720. [CrossRef] [PubMed]

38. Betancort, J.M.; Sakthivel, K.; Thayumanavan, R.; Tanaka, F.; Barbas III, C.F. Catalytic Direct Asymmetric Michael Reactions: Addition of Unmodified Ketone and Aldehyde Donors to Alkylidene Malonates and Nitro Olefins. Synthesis 2004, 2004, 1509-1521. [CrossRef]

39. Kaplaneris, N.; Koutoulogenis, G.; Raftopoulou, M.; Kokotos, C.G. 4-Fluoro and 4-Hydroxy Pyrrolidine-thioxotetrahydropyrimidinones: Organocatalysts for Green Asymmetric Transformations in Brine. J. Org. Chem. 2015, 80, 5464-5473. [CrossRef]

40. Patil, M.P.; Sunoj, R.B. The role of noninnocent solvent molecules in organocatalyzed asymmetric michael addition reactions. Chem. Eur. J. 2008, 14, 10472-10485. [CrossRef] [PubMed]

41. Saito, T.; Isogai, A. TEMPO-Mediated Oxidation of Native Cellulose. The Effect of Oxidation Conditions on Chemical and Crystal Structures of the Water-Insoluble Fractions. Biomacromolecules 2004, 5, 1983-1989. [CrossRef]

42. Jalal, S.; Sarkar, S.; Bera, K.; Maiti, S.; Jana, U. Synthesis of nitroalkenes involving a cooperative catalytic action of iron(III) and piperidine: A one-pot synthetic strategy to 3-alkylindoles, $2 \mathrm{H}$-chromenes and $\mathrm{N}$-arylpyrrole. Eur. J. Org. Chem. 2013, 2013, 4823-4828. [CrossRef]

43. Kondo, T.; Kose, R.; Naito, H.; Kasai, W. Aqueous counter collision using paired water jets as a novel means of preparing bio-nanofibers. Carbohydr. Polym. 2014, 112, 284-290. [CrossRef]

44. Syu, S.; Kao, T.-T.; Lin, W. A new type of organocatalyst for highly stereoselective Michael addition of ketones to nitroolefins on water. Tetrahedron 2010, 66, 891-897. [CrossRef]

Sample Availability: All data generated and/or compound samples analyzed during this study are included in this article and are available from the corresponding author on reasonable request. 